\title{
Olfactory Dysfunction in Schizophrenia: A Qualitative and Quantitative Review
}

Paul J. Moberg, Ph.D., Rachel Agrin, B.S., Raquel E. Gur, M.D., Ph.D., Ruben C. Gur, Ph.D., Bruce I. Turetsky, M.D., and Richard L. Doty, Ph.D.

Olfactory dysfunction in patients with schizophrenia has been a topic of increasing interest, with deficits in odor identification, detection threshold sensitivity, discrimination, and memory being reported. Despite increasing knowledge, controversy has existed about possible differential deficits among olfactory tests as well as the influences of gender, smoking, and medication status on olfactory measures. To help elucidate some of this controversy, we conducted a qualitative and quantitative (meta-analytic) review of the English language literature on olfaction in schizophrenia. Moderator variables such as gender, medication status, and smoking history were also examined. Results indicated that substantial olfactory deficits, across all domains, are observed in patients with schizophrenia. No differential deficits were observed across domains of odor identification, detection threshold sensitivity, discrimination, and memory. The influences of gender, medication status, and smoking on effect sizes were not significant across studies. This supports the hypothesis of primary dysfunction in the olfactory system that is regulated by brain regions where structural and functional abnormalities have also been reported in neuroimaging studies. [Neuropsychopharmacology 21:325-340, 1999] (C) 1999 American College of Neuropsychopharmacology. Published by Elsevier Science Inc.
KEY WORDS: Olfaction; Smell; Schizophrenia; Review; Meta-analysis

There is growing evidence to suggest that schizophrenia is a neurobehavioral disorder affecting temporallimbic brain systems (Fuster 1989; Seidman et al. 1995; Weinberger et al. 1992).

Neuropsychological, structural, and functional imaging studies converge in reporting selective impairments in memory and attention and, correspondingly,

From the Brain-Behavior Laboratory, Department of Psychiatry (PJM, RA, REG, RCG, BIT) and the Smell and Taste Center (PJM, RLD), Department of Otorhinolaryngology: Head and Neck Surgery, University of Pennsylvania School of Medicine, Philadelphia, PA.

Address correspondence to: Paul J. Moberg, Ph.D., Brain-Behavior Laboratory, Department of Psychiatry, $10^{\text {th }}$ Floor, Gates Building, Hospital of the University of Pennsylvania, 3400 Spruce Street, Philadelphia, PA 19104.

Received October 28, 1998; revised December 23, 1998; accepted January 07, 1999. neuroanatomic and physiologic abnormalities in the temporal and frontal lobe areas underlying these cognitive domains (Andreasen et al. 1990; Calev et al. 1983; Gur et al. 1985, 1995; McCarley et al. 1991; Saykin et al. 1991; Shenton et al. 1992; Turetsky et al. 1995).

Efforts to characterize the nature of these deficits and their clinical correlates have employed a variety of methods and an array of neurobehavioral probes evaluating memory, executive function, and vigilance during physiologic measures of cerebral activity. Olfaction is relatively neglected, but in many ways a heuristically useful probe of frontal and temporal limbic system physiology. Olfactory processing is mediated by limbic neuroanatomical structures that have been implicated in the pathophysiology of schizophrenia, particularly the prefrontal cortex, ventromedial temporal lobe, basal forebrain and diencephalon. Contrary to an initial consideration of olfaction as a circumscribed and perhaps isolated system, there are reasons to believe that olfaction is linked to several important cognitive and emo- 
tional domains and associated brain regions with which it shares connectivity and substrate. The olfactory system is unique in that few synapses lie between the receptors and primary olfactory cortex, providing one of the most direct links between the brain and environment. Several studies have now reported that patients with schizophrenia exhibit deficits in olfactory function. These deficits are seen early in the course of the disorder, but are strongly correlated with duration of illness (Kopala et al. 1992; Moberg et al. 1997b). Neuroleptic use, smoking, cognitive deficits and illness severity all appear to be unrelated to this abnormality (Martzke et al. 1997). With the recently increased interest in the use of olfactory measures in patients with schizophrenia, several issues have emerged. A review of this literature could help evaluate what seems to be well established and point to avenues for further research. The current review seeks to examine the following areas: 1 ) review the relevant neuroanatomy and neurochemistry of the olfactory system; 2) describe the theoretical functions of the olfactory system; 3) review psychophysical test findings in patients with schizophrenia; 4) examine the genetic studies performed in this area; 5) review functional neuroimaging studies of the olfactory system in patients with schizophrenia; and 6) define potential differential deficits in olfactory functioning in this patient group as well as identify possible moderator variables. In order to address the latter question, we conducted a meta-analytic review of the olfactory system in four domains of olfactory functioning (i.e., detection threshold sensitivity, discrimination, identification, and memory).

\section{NEUROANATOMY OF THE OLFACTORY SYSTEM}

Olfactory processing is mediated by a set of limbic structures that have been implicated in the pathophysiology of schizophrenia, particularly the prefrontal cortex, ventromedial temporal lobe, basal forebrain, and diencephalon (Arnold and Trojanowski 1996). The olfactory system is unique in that only one synapse lies between the receptors and primary olfactory cortex, providing one of the most direct links between the brain and environment (Eslinger et al. 1982; Price 1990). Olfactory anatomy and physiology have been reviewed and will not be extensively detailed here (Doty 1991a; Eslinger et al. 1982; Greer 1991; Kratskin 1995; Price 1990). Briefly, odorants come in contact with the olfactory system when a stream of air is drawn through the nostrils. The air is then warmed, humidified, and filtered as it passes through the mucosa of the three baffle-shaped turbinate bones, or conchae, in the upper portion of the nasal cavity. The first cranial nerve is made up of millions of bipolar receptor cells whose cell bodies, dendrites, and initial axon segments are found within the olfactory epithelium, a heterogeneous area of tissue located on the cribriform plate, superior septum, and portions of the superior and middle turbinates (Moran et al. 1982). The unmyelinated axons of the olfactory receptor cells form bundles constituting the olfactory fila that traverse the foramina of the cribriform plate, forming a thick layer of axons on the surface of the olfactory bulb ipsilateral to their origin. The olfactory bulbs rest in the olfactory sulcus of the orbitalfrontal cortex, and axons from mitral and tufted (second order) cells leave the bulb via the lateral and medial olfactory striae. While the latter has been thought to project medially into olfactory tubercle and anterior perforated substance (Eslinger et al. 1982; Price 1987), more recent studies have suggested that there is no functional medial olfactory tract in mammals (Price 1990). The lateral olfactory tract projects to the anterior olfactory nucleus, olfactory tubercle, prepiriform cortex, piriform cortex, periamygdaloid complex, and corticomedial amygdala. It also projects to an area of great interest in schizophrenia-entorhinal cortex-a major source of efferent fibers to the hippocampus (Lewis and Shute 1967; Shute and Lewis 1967). Secondary projections from olfactory cortex include those to orbitofrontal cortex (many via the dorsomedial thalamus, but some directly through cortico-cortical projections from prorhinal cortex to the posterolateral orbitofrontal region) (Potter and Nauta 1979; Tanabe et al. 1975), submedial thalamus, lateral hypothalamus, and nucleus accumbens.

As noted above, the olfactory system is unique in that, unlike other sensory systems, the primary projections are ipsilateral and therefore may provide a unique opportunity to probe for lateralized deficits in hemispheric processing of olfactory information in patients with schizophrenia. Despite the potential in exploiting the neural substrate and configuration of this system, only one published study to date has presented stimuli to each nostril separately in patients with schizophrenia (Dunn and Weller 1989). By contrast, there have been a number of studies in the neurologic literature which have examined the unilateral presentation of olfactory stimuli (Doty 1991a; Doty et al. 1997). In epilepsy, for example, studies have generally observed decrements in olfactory abilities in the nostril ipsilateral to the ablation site (West and Doty 1995). While the Dunn and Weller (1989) study did not observe differential nostril effects, future studies examining unilateral presentation of olfactory stimuli will be important in delineating possible lateralized impairment in olfactory function in patients with schizophrenia.

In general, deficits in the ability to smell in patients with schizophrenia have been thought to arise from pathologic damage or dysfunction in central olfactory brain regions. However, the occurrence of dystrophic neurites in olfactory epithelium (OE) of patients with 
neurodegenerative disorders such as Alzheimer disease (AD) also support the possibility that olfactory deficits are a result of damage to one or more cell populations of the sensory epithelium. In order to directly assess this question in neuropsychiatric disorders, Smutzer and colleagues (1998) performed the first detailed immunohistochemical analysis of postmortem human olfactory tissue from six well-characterized elderly people with schizophrenia and five non-neuropsychiatric controls. In this study, a number of neuronal proteins were qualitatively examined including microtubuleassociated proteins (MAP1B), neural cell adhesion molecule (N-CAM), various neurofibrillary (NF) proteins, protein gene product 9.5 (PGP 9.5), low-affinity nerve growth factor receptor (NGFR), synaptophysin, and glial fibrillary acidic protein. Results indicated that both groups exhibited dystrophic neurites that were immunoreactive for synaptophysin, MAP1B, and neurofilament proteins. Overall, no significant histochemical or morphologic differences in either the expression or distribution of these proteins were observed in the OE of patients with schizophrenia compared to control subjects. The absence of major immunocytochemical differences in $\mathrm{OE}$ between patients and controls suggest that any observed olfactory deficits in patients with schizophrenia are likely to be central (i.e., CNS) in origin. While an exhaustive review of the cellular and molecular neuropathology of the olfactory system in schizophrenia and neurodegenerative disease is not possible here, the reader is referred to a comprehensive analysis by Arnold and colleagues (1998).

\section{NEUROCHEMISTRY OF THE OLFACTORY SYSTEM}

The neurochemistry of the olfactory system is highly complex due to the wide variety of neurotransmitters and putative neuroactive peptides represented (Greer 1991). Given this complexity, a detailed review is beyond the scope of this paper. For more comprehensive and critical reviews the reader should refer to Halász (1990), Kratskin (1995), and Margolis and Getchell (1988). A current summary of the neurochemical organization of the olfactory bulb is presented in Figure 1.

While the neurotransmitters utilized by mitral, deep, and middle tufted cells have not been unequivocally established, there is evidence that one or more of the following are involved: one of the excitatory amino acids, glutamate, aspartate, or the polypeptide $\mathrm{N}$-acetylaspartylglutamate (Greer 1991). High levels of N-methylD-aspartate (NMDA) receptors are found in the external plexiform layer (where presynaptic dendritic specializations of mitral cells occur) and increased levels of NMDA receptors in piriform cortex where mitral cell axons terminate (Cotman et al. 1987). Indeed, a recent review by Ellison (1995) examines the link between NMDA antagonists and psychosis. The author notes that such agents have been shown to induce neuronal degeneration in brain regions of rats related to olfaction, associated limbic structures such as piriform cortex and posterior regions of entorhinal cortex and in its projections, through the perforant pathway, to dentate gyrus and other cells in ventral hippocampus. There is anatomical and functional (olfactory) evidence that alterations in these same limbic structures are present in patients with schizophrenia.

\section{FUNCTIONAL ASPECTS OF THE OLFACTORY SYSTEM}

Olfactory function has historically been divided into two presumably hierarchical and independent processes, the first being "peripheral" (i.e., acuity or the ability to detect an odor) and the second being "central" (i.e., identification, discrimination, memory or the ability to name, discriminate between or remember an odor). Deficits in acuity have been thought to reflect impairment in peripheral processes (e.g., defect in epithelium or mucosa), while deficits in identification or memory reflect higher order or central impairment (e.g., defect in higher order brain processes). This notion is based on studies that described impaired odor identification skills with preserved threshold ability in patients with lesions to the orbitofrontal cortex (Potter and Butters 1980), dorsomedial nucleus of the thalamus (Adams and Victor 1985), and excision of the orbitofrontal cortex (Jones-Gotman and Zatorre 1988). Given this definition, the peripheral system must be functioning for an odor to be perceived.

While this notion makes intuitive sense, there have been few empirical studies that directly support such a dichotomy of function. In addition, there are several methodological concerns that also exist. For example, potential confounds due to differential task difficulty has been an ongoing problem in many areas of behavioral research (Chapman and Chapman 1978) and also afflicts different olfactory measures. As noted by Doty and colleagues (1995) odor detection threshold tasks typically tend to be less reliable than tests of odor identification, especially when fewer trials or reversals are used. As such, any differential deficit between odor identification and odor detection threshold may simply reflect the different reliabilities of respective instruments. It is also possible that measures of four seemingly different olfactory processes (identification, threshold, discrimination, memory) actually tap one larger olfactory domain, in that a similar construct is being measured in each case. For example, Doty et al. (1994) in a principal components analysis of various tests of olfactory func- 


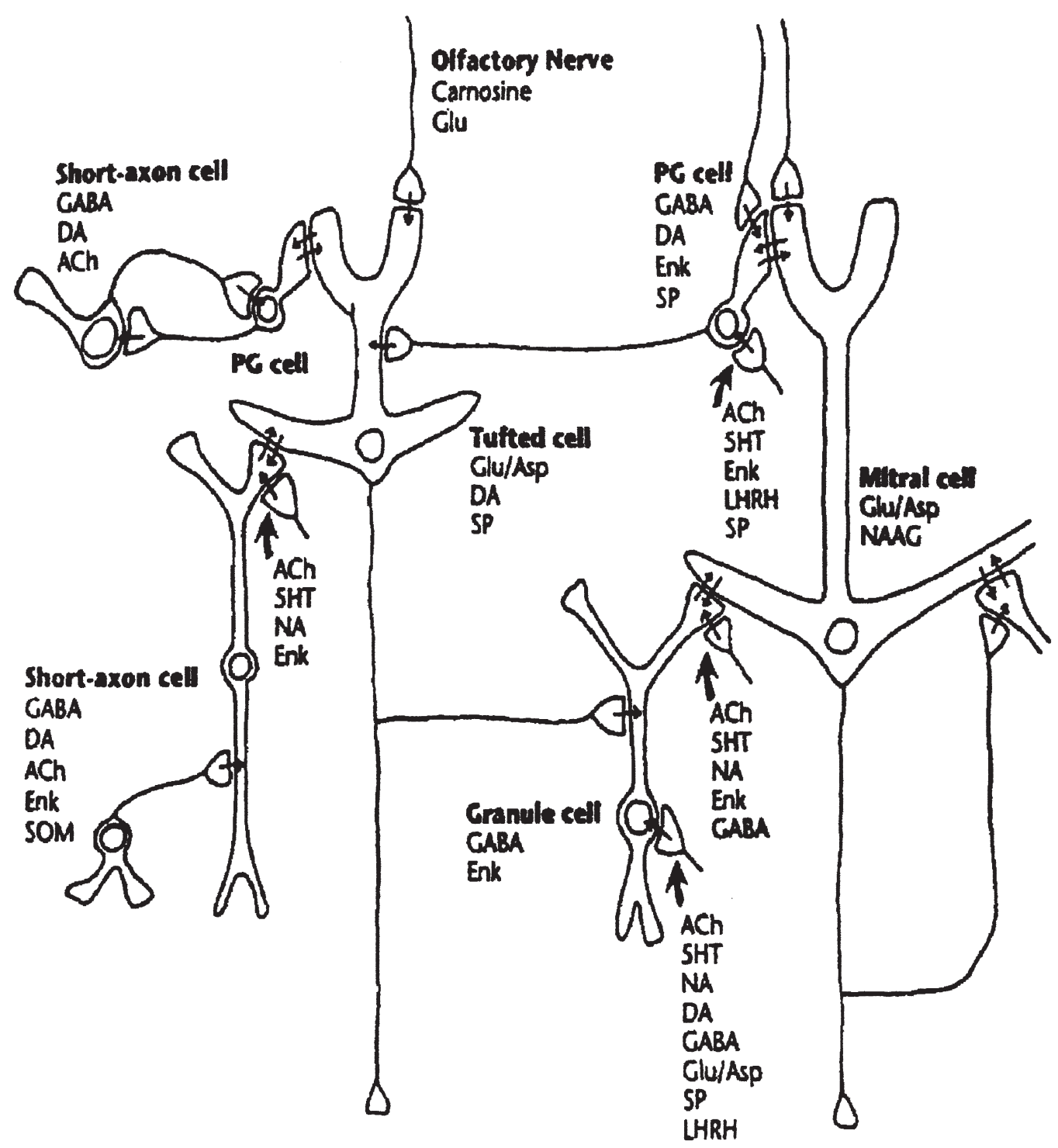

Figure 1. Schematic diagram of the major neurotransmitter and neuromodulator substances for bulbar neurons as well as peripheral and central afferent fibers. Ach, acetylcholine; DA, dopamine; Enk, methionine-enkephalin; Glu/Asp, glutamate or aspartate; $5 \mathrm{HT}$, serotonin; LHRH, luteinizing hormone-releasing hormone; NA, noradrenaline; NAAG, N-acetyl-aspartyl-glutamate; PG cell, periglomerular cell; SOM, somatostatin; SP, substance P. Small arrows denote the direction of synaptic transmission; solid arrows denote centrifugal inputs to the olfactory bulb. Reprinted from Doty RL (1995), Handbook of Olfaction and Gustation, by courtesy of Marcel Dekker, Inc.

tion, found that, in healthy people, most tests load on a single "olfactory" factor. Comparable analyses of olfactory function in neurologic and neuropsychiatric patients will prove important to see if a similar loading on a single olfactory factor is seen. Lastly, some of the studies arguing a central versus peripheral defect are of patients who have undergone temporal lobectomy for intractable seizures (Eichenbaum et al. 1983; Eskenazi et al. 1986). However, other work investigating olfactory impairment in patients with temporal lobe lesions (Rausch and Serafetinides 1975) did not yield similar results. These discrepant findings may be due to differences in the measures and procedures employed, and it is fur- ther possible that the epileptic participants in the studies may have demonstrated olfactory deficits before surgical intervention (West and Doty 1995; Martinez et al. 1993). Overall, it appears that the notion of "peripheral" and "central" deficits, while heuristically compelling, is more complex and difficult to separate than previously believed. In future studies, a within subjects experimental design that employs multiple types of olfactory measures (i.e., identification, threshold, discrimination, memory, etc.) will allow a more direct assessment of the question of differential task impairment.

Most odorants have the propensity to stimulate both olfactory receptors (CN I) positioned in the upper re- 
cesses of the nasal cavity and free nerve endings of the ophthalmic and maxillary divisions of the trigeminal nerve (CN V), distributed throughout the nasal mucosa and olfactory neuroepithelium. Sensations resulting from CN I stimulation are those of odors (e.g., the "smell" of flowers, grass, orange). In contrast, sensations from stimulation of $\mathrm{CN} \mathrm{V}$ are somatosensory, and include tactile sensations, burning, cooling, tickling, pungency, warming, and the perception of atmospheric humidity. While the full anatomy and physiology of the trigeminal system cannot be covered in detail here, it is important to realize that a variety of odorants differentially stimulate these two systems (Doty et al. 1978). As such, CN I and CN V differ with regard to their central projections and the degree to which their pathways project both contralaterally and ipsilaterally (Price 1990). Thus, when choosing odorants for use in olfactory assessment, careful consideration of their trigeminal properties is important to assure stimulation of the primary olfactory pathways and associated brain structures. For example, the odorants n-butanol and pyridine have stronger trigeminal components than do more purely olfactory stimulants such as phenyl ethyl alcohol or vanillin, and, as such, may confound $\mathrm{CN}$ I and $\mathrm{CN} \mathrm{V}$ functions (Doty et al. 1978).

\section{PSYCHOPHYSICAL FINDINGS}

Since the pioneering psychophysical studies of olfactory recognition memory in patients with schizophrenia by Campbell and Gregson (1972), a number of studies have reported that schizophrenia patients evidence olfactory dysfunction, although the magnitude of such dysfunction appears to be less than that seen in Alzheimer and idiopathic Parkinson disease (for reviews, see Doty 1991b; Harrison and Pearson 1989; Martzke et al. 1997; Pantelis and Brewer 1995; Serby et al. 1992). For example, Bradley (1984) reported that psychotic patients, most notably men with schizophrenia, were hypersensitive to the pheromonal substance $5 \alpha$-16-androsten-3-one. More recent studies, however, have not confirmed such hypersensitivity, with some studies reporting intact sensitivity (Kopala et al. 1989; Kopala et al. 1992; Geddes et al. 1991) and others demonstrating decreased olfactory sensitivity in this disease (Isseroff et al. 1987; Serby et al. 1990). With the exception of one study (Warner et al. 1990; see also response by Hurwitz and Clark 1990), deficits in odor identification (Brewer et al. 1996; Houlihan et al. 1994; Hurwitz et al. 1988; Kopala et al. 1989; Kopala et al. 1992; Kopala et al. 1994; Kopala et al. 1995b; Kopala et al. 1995c; Malaspina et al. 1994; Moberg et al. 1997a; Moberg et al. 1997b; Seidman et al. 1992; Seidman et al. 1995; Seidman et al. 1997; Serby et al. 1990; Wu et al. 1993), odor detection threshold sensitivity (Isseroff et al. 1987; Serby et al. 1990), and odor memory (Campbell and Gregson 1972; Wu et al. 1993) have now been reported. Sreenivasan and colleagues (1987) also described deficits in schizophrenia patients in the ability to discriminate between different odors on a match to sample task. Dunn and Weller (1989), however, did not find similar discrimination deficits when testing each nostril separately or bilaterally in their sample of patients and controls.

With regard to odor identification, Kopala and colleagues $(1989,1997 b)$ have suggested that men evidence greater olfactory impairment than women with schizophrenia. This hypothesis is based on Kopala's 1989 study of 41 patients with schizophrenia where poorer UPSIT performance was observed in males relative to females after accounting for normal sex effects (as women typically perform better than men on tests of olfactory function). Other studies, however, have not replicated this finding (Houlihan et al. 1994; Kopala et al. 1995c; Malaspina et al. 1994; Moberg et al. 1997a; Moberg et al. 1997b; Seidman et al. 1997), perhaps implicating other moderator variables in this deficit (e.g., longer duration of illness and/or preponderance of negative symptoms in males).

\section{GENETIC STUDIES}

A possible genetic contribution to the olfactory dysfunction of schizophrenia was first suggested by Kopala and colleagues (1991) in a report of olfactory agnosia in two members of a family with a partial trisomy of chromosome 5 and schizophrenia. Along this same line, Kwapil and associates (1996) found that deviant olfactory experiences in an initially nonpsychotic sample predicted the development of clinical psychosis at a 10year reevaluation. Of their subjects who reported olfactory experiences (i.e., misperceptions, hallucinations) at the baseline assessment, significantly higher rates of psychosis-like experiences, schizotypal symptoms, and poorer overall levels of functioning were observed at follow-up. Becker and colleagues (1993) examined olfactory event-related potentials (OERP) in a sample of "psychosis prone" subjects using pleasant (vanillin) and unpleasant (hydrogen sulfide) odors as physiologic probes. Results indicated that psychosis prone subjects who scored high on 'physical anhedonia' showed higher OERP amplitudes in response to vanillin, whereas subjects who scored high on 'perceptual aberration' showed smaller OERP amplitudes to hydrogen sulfide. Most recently, Park and Schoppe (1997) also observed odor identification deficits in psychometrically ascertained schizotypic men. Overall, these studies suggest that subjects at risk for psychosis may experience unusual olfactory experiences, show psychophysical deficits, or demonstrate aberrant physiologic responses to olfactory stimuli that may underlie an "olfactory risk factor" 
or "marker" for schizophrenia. These data argue for the examination of family members and unaffected siblings of patients with schizophrenia to assess for the presence of any preclinical olfactory deficit. Indeed, a recent study by Kopala et al. (1997a) examined odor identification in 12 pairs of monozygotic twins discordant for schizophrenia and found that the combined twin group differed from healthy controls in performance on the University of Pennsylvania Smell Identification Test (UPSIT) (Doty et al. 1984). However, affected and unaffected twins did not differ from each other. Similarly, recent studies of UPSIT performance in patients with questionable Alzheimer disease (Nordin and Murphy 1996) and in family members of AD patients (Serby et al. 1996) show significant deficits in performance, suggesting a genetic vulnerability to olfactory dysfunction in this disorder as well. In contrast, studies of the genetic contributions to the olfactory deficit seen in Huntington's disease (HD) have indicated the absence of olfactory dysfunction in at-risk family members (Moberg and Doty 1997) and asymptomatic gene carriers (Bylsma et al. 1997), suggesting that if preclinical deficits exist in HD, most occur at or near the time motor symptoms become apparent.

\section{FUNCTIONAL IMAGING STUDIES}

Given the relevance of the neural substrate, and the evidence of psychophysical performance deficits, physiologic probes of the integrity of the olfactory system hold special promise for illuminating aspects of the neuropathology underlying schizophrenia. There are multiple technologies including positron emission tomography (PET), single photon emission tomography (SPECT), event-related potentials (ERP) and functional MRI (fMRI) to study the functional anatomy of cognitive, sensory, and motor abilities. To date, however, there has been comparatively little application of these techniques to olfaction (for review see Doty et al. 1997). Several studies, however, have evaluated metabolic activity in olfactory-related regions in patients with schizophrenia.

Clark et al. (1991) examined regional cerebral glucose metabolism in 16 male schizophrenia patients and eight healthy male controls. Eight of the patients had normal olfactory function and eight were microsmic, as determined by scores on the UPSIT. Results showed that, as a group, patients had lower rates of overall frontal metabolism relative to healthy controls. However, the microsmic patients had lower right basal ganglia and thalamic metabolism than the normosmic patients, suggesting dysfunction in subcortical brain regions associated with olfaction. While limited in sample size, this study argues for a relative decrement in right hemisphere brain regions and increased activity in contralat- eral left hemisphere regions in olfactory-deficient schizophrenia patients.

Wu et al. (1993) examined odor memory and identification ability in 28 healthy control and 20 neurolepticnaive patients with schizophrenia, some of whom also underwent concurrent PET scanning. Among the patients with schizophrenia, significant correlations were observed between UPSIT scores and degree of regional metabolism in the frontal lobes, especially in the left middle frontal and left inferior frontal gyri. The left frontal/occipital ratio was also positively related to UPSIT performance. The relationship between the olfactory measures and regional metabolism measures in this study could be confounded, however, by the fact that the stimulation task during the PET procedure was a visual continuous performance task rather than an olfactory activation task or resting baseline.

Bertollo et al. (1996) examined local cerebral metabolic rate within two olfactory cortical projection areas in eight healthy males and eight males with schizophrenia. Results revealed a greater degree of hypometabolism in the right lateroposterior quadrant of the orbitofrontal cortex, which receives mainly uncrossed projections from the olfactory bulbs via the pyriform and entorhinal cortex, along with a small number of olfactory and other limbic inputs from the medial subdivision of the dorsomedial thalamic nucleus. A smaller but more symmetrical hypometabolism was seen in the medial anterior aspect of the orbitofrontal cortex, which receives crossed afferents from the limbic system. While the authors did not obtain psychophysical measures of olfactory function nor clinically define olfactory dysfunction in these subjects, these data are generally consistent with the notion that the olfactory deficit in schizophrenia is reflective of a rhinencephalic deficit that is more pronounced in the right hemisphere.

Malaspina and colleagues (1996) examined six males with a diagnosis of schizophrenia and seven age- and sex-matched controls using single photon emission computed tomography (SPECT). Resting baseline (matching pictures without delay) and activation (birhinal stimulation with UPSIT items) data were obtained. The authors found a contiguous cluster in right cortical areas with significantly lower regional cerebral blood flow (rCBF) in schizophrenia patients relative to controls. Notably, controls, but not schizophrenia patients, had significantly increased rCBF in olfactory activation than in resting conditions. Activation was seen in the right hippocampus, right medial temporal/lateral, left occipital, and left medial temporal lobes. This study suggests deficient activation of the tertiary cortical and medial temporal lobe olfactory areas in patients with schizophrenia.

Despite the small number of studies and heterogeneity of methods, these studies suggest a slight right hemisphere predominance for the processing of olfac- 
tory information. Nevertheless, left hemisphere regions also appear to be important in olfactory processing, but seem to be less activated by olfactory stimuli both in patients and controls. However, only one of these studies used an activation paradigm with olfactory stimuli (Malaspina et al. 1996). The remainder correlated psychophysical scores with functional indices. The use of olfactory stimuli in activation paradigms could prove important in better defining the regions involved and pattern of activation seen in the processing of olfactory information in patients with schizophrenia.

\section{DIFFERENTIAL IMPAIRMENT IN OLFACTORY FUNCTION}

Despite the increasing interest in olfactory abilities in patients with schizophrenia, very few studies have explored the severity of olfactory dysfunction with regard to the psychophysical tests employed and olfactory domains assessed (i.e., identification, threshold, discrimination recognition). Given the purported differences in neuroanatomic loci for these different olfactory domains, it may be expected that olfactory impairment would be differentially manifested in this disorder. In addition, possible moderator variables such as gender, medication, and smoking history have been inconsistently dealt with in most studies.

To address this controversy more definitively, we reviewed the English language literature on olfactory function in schizophrenia and employed meta-analytic procedures, which incorporated effect size of each study as the unit of analysis to examine the influences of schizophrenia on four olfactory domains. Effect size is defined as the magnitude of the mean difference between patient and control groups on a given measure, expressed in standard deviation units (Rosenthal 1986). Such procedures are superior to the traditional method of tallying statistically significant and non-significant results used in most narrative reviews, because the latter method disproportionately penalizes highly reliable studies with null findings. In the current analysis, the primary effect size examined is the difference between schizophrenia patients and healthy controls on measures of olfactory identification, detection threshold, discrimination and recognition memory.

\section{METHODS}

\section{Selection of Studies}

An extensive literature review of English-language studies of olfactory function in schizophrenia patients and healthy controls published before October 1997 was conducted via online databases (Medline and PsycInfo) and reference lists from review articles. This liter- ature search yielded 24 publications. Of these publications, 23 were deemed suitable for meta-analysis. Due to the inclusion of more than one relevant study of olfactory function in several of these publications (e.g., both identification and threshold assessed), 25 studies (out of 23 publications) were ultimately found to be appropriate for meta-analytic review. Studies that lacked control groups $(\mathrm{N}=2$; Clark et al. 1991; Kopala et al. 1991), that presented incomplete or unusable data $(\mathrm{N}=$ 2; Bradley 1984; Campbell and Gregson 1972), or that utilized samples that were judged to overlap with other samples ( $\mathrm{N}=1$; Serby et al. 1992), were excluded. Table 1 presents individual study characteristics and effect size estimates for schizophrenia patients for tests of olfactory identification, threshold, discrimination, and memory, respectively.

\section{Methodological Variables}

As can be seen in Table 1, the type of olfactory test used in the domain of odor identification was quite homogeneous. In contrast, in the studies examining odor detection threshold, discrimination, and memory there was greater heterogeneity with regard to the odorant types used. Given this variability, we sought to define olfactory function in these latter measures more broadly by incorporating all method types within a given domain.

Eighteen of the 25 studies were categorized under the domain of olfactory identification. With the exception of one study which used a Yes/No identification task (Serby et al. 1990), the remainder utilized the UPSIT (Doty et al. 1984) in the assessment of odor identification abilities. In this test, a subject is required to identify, in a four-alternative multiple choice format, each of 40 odorants presented on microencapsulated "scratch and sniff" labels. For example, one of the test items reads: "This odor smells most like: [a] chocolate; [b] banana; [c] onion; or [d] fruit punch". The subject must provide a response even if no odor is perceived (i.e., the test is forced-choice). The dependent measure is the number of items correctly answered. The reliability and validity of the UPSIT have been described in detail elsewhere (Doty et al. 1984, Doty 1989).

Four studies met criteria for the domain of olfactory threshold. Studies that were categorized under this domain included instruments that determined the lowest concentration at which a subject was able to detect a particular odorant. All studies incorporated a variant of a ascending method of limits (AML) procedure. In this forced-choice task, odorants are presented sequentially from low to high concentrations and the point of transition between detection and no detection is estimated (Doty and Kobal 1995).

Two studies met criteria for inclusion in the domain of olfactory discrimination. Studies included under this domain included tasks that measure an individuals 
Table 1. Studies of Olfactory Function in Patients with Schizophrenia

\begin{tabular}{|c|c|c|c|c|c|c|}
\hline Author and Year & Type of Test & $\begin{array}{c}\text { Test Mean } \\
( \pm S D)\end{array}$ & $\begin{array}{c}\text { Number of } \\
\text { Samples }\end{array}$ & Sex & $\begin{array}{c}\text { Mean Age } \\
( \pm \text { SD) [range] }\end{array}$ & $\begin{array}{c}\text { Effect Size } \\
\text { (Cohen's) }\end{array}$ \\
\hline \multicolumn{7}{|l|}{ Olfactory Identification } \\
\hline \multirow[t]{2}{*}{ Brewer et al. 1996} & UPSIT & $27.3(6.5)$ & 27 Schiz & $27 \mathrm{~m}$ & $31.8(8.5)$ & 0.9458 \\
\hline & & $32.3(2.4)$ & 19 Control & $19 \mathrm{~m}$ & $34.8(12.5)$ & \\
\hline \multirow[t]{2}{*}{ Houlihan et al. 1994} & UPSIT & $35.0(3.6)$ & 42 Schiz $^{a}$ & $23 \mathrm{~m}, 19 \mathrm{f}^{a}$ & $33.25(6.8)^{a}$ & 0.6792 \\
\hline & & $37.1(1.4)$ & 37 Control & $22 \mathrm{~m}, 15 \mathrm{f}$ & $31.6(7.5)$ & \\
\hline \multirow[t]{2}{*}{ Hurwitz et al. 1988} & UPSIT & $33.4(5.7)$ & 18 Schiz & $15 \mathrm{~m}, 3 \mathrm{f}$ & 23.9 [17-41] & 0.8916 \\
\hline & & $37.7(1.4)$ & 10 Control & $7 \mathrm{~m}, 3 \mathrm{f}$ & $33.6[21-43]$ & \\
\hline \multirow[t]{2}{*}{ Kopala et al. 1989} & UPSIT & $?$ & 41 Schiz & $26 \mathrm{~m}, 15 \mathrm{f}$ & $25.8[18-54]$ & 0.9611 \\
\hline & & & 43 Control & $23 \mathrm{~m}, 20 \mathrm{f}$ & $29.6[18-54]$ & \\
\hline \multirow[t]{2}{*}{ Kopala et al. 1992} & UPSIT & $?$ & 40 Schiz & $30 \mathrm{~m}, 10 \mathrm{f}$ & $26.6(7.7)$ & 0.5629 \\
\hline & & & 58 Control & $28 \mathrm{~m}, 30 \mathrm{f}$ & $28.5(7.8)$ & \\
\hline \multirow[t]{2}{*}{ Kopala et al. 1994} & UPSIT & $34.6(5.0)$ & 131 Schiz & $92 \mathrm{~m}, 38 \mathrm{f}^{b}$ & $27.3(7.8)$ & 0.6846 \\
\hline & & $37.4(1.5)$ & 77 Control & $30 \mathrm{~m}, 47 \mathrm{f}$ & $32.5(11.1)$ & \\
\hline \multirow{2}{*}{ Kopala et al. 1995c } & UPSIT & $?$ & 65 Schiz & $49 \mathrm{~m}, 16 \mathrm{f}$ & $29.8(8.2)$ & 0.6140 \\
\hline & & & 30 Control & $14 \mathrm{~m}, 16 \mathrm{f}$ & $34.3(8.2)$ & \\
\hline \multirow[t]{2}{*}{ Kopala et al. 1995b } & UPSIT & $?$ & 27 Schiz & $27 f$ & $44.0(6.9)$ & 2.0724 \\
\hline & & & 25 Control & $25 f$ & $46.2(8.3)$ & \\
\hline \multirow[t]{2}{*}{ Malaspina et al. 1994} & UPSIT & $29.8(5.8)$ & 20 Schiz & $15 \mathrm{~m}, 5 \mathrm{f}$ & $33.25(5.9)$ & 1.6918 \\
\hline & & $37.4(2.0)$ & 20 Control & matched & matched & \\
\hline \multirow[t]{2}{*}{ Moberg et al. 1997a } & UPSIT & $18.6(7.8)$ & 16 Schiz & $4 \mathrm{~m}, 12 \mathrm{f}$ & $77.9(6.5)$ & 3.1778 \\
\hline & & $36.5(2.5)$ & 20 Control & $6 \mathrm{~m}, 14 \mathrm{f}$ & $72.5(6.4)$ & \\
\hline \multirow[t]{2}{*}{ Moberg et al. 1997b } & UPSIT & $27.3(9.8)$ & 38 Schiz & $18 \mathrm{~m}, 20 \mathrm{f}$ & $50.6(25.5)$ & 1.3709 \\
\hline & & $37.0(2.1)$ & 40 Control & $18 \mathrm{~m}, 22 \mathrm{f}$ & $49.6(24.6)$ & \\
\hline \multirow[t]{2}{*}{ Seidman et al. 1992} & UPSIT & $33.2(3.8)$ & 16 Schiz & $15 \mathrm{~m}, 1 \mathrm{f}$ & $36.5(8.1)$ & 1.3432 \\
\hline & & $37.6(2.5)$ & 17 Control & $16 \mathrm{~m}, 1 \mathrm{f}$ & $31.7(8.9)$ & \\
\hline \multirow[t]{2}{*}{ Seidman et al. 1995} & UPSIT & $32.5(7.0)$ & 17 Schiz $^{a}$ & $14 \mathrm{~m}, 4 \mathrm{f}^{c}$ & $39.8(8.3)^{c}$ & 0.9251 \\
\hline & & $37.8(2.2)$ & 12 Control & $10 \mathrm{~m}, 4 \mathrm{f}$ & $39.6(11.2)$ & \\
\hline \multirow[t]{2}{*}{ Seidman et al. 1997} & UPSIT & $33.3(6.1)$ & 40 Schiz & $24 \mathrm{~m}, 16 \mathrm{f}$ & $38.5(6.5)$ & 0.6135 \\
\hline & & $36.4(3.1)$ & 32 Control & $15 \mathrm{~m}, 17 \mathrm{f}$ & $36.4(9.3)$ & \\
\hline \multirow[t]{2}{*}{ Serby et al. 1990} & UPSIT & $27.8(?)$ & 14 Schiz & $14 \mathrm{~m}$ & matched, & 1.7522 \\
\hline & & $39.0(?)$ & 14 Control & $?$ & {$[40-49]$} & \\
\hline \multirow[t]{2}{*}{ Serby et al. 1990} & Yes/No & $0.676(?)$ & 14 Schiz & $14 \mathrm{~m}$ & matched, & 0.7745 \\
\hline & ID & 0.709 (?) & 14 Control & $?$ & [40-49] & \\
\hline \multirow[t]{2}{*}{ Warner et al. 1990} & UPSIT & $36.0(3.0)$ & 12 Schiz & $12 \mathrm{~m}$ & $34[20-42]$ & 0.7839 \\
\hline & & $38.0(1.1)$ & 8 Control & $8 \mathrm{~m}$ & $32[20-44]$ & \\
\hline Wu et al. 1993 & UPSIT & $32.1(9.5)$ & 20 Schiz & $19 \mathrm{~m}, 1 \mathrm{f}$ & $32.1(9.3)$ & 0.7786 \\
\hline & & $37.2(2.0)$ & 24 Control & $23 \mathrm{~m}, 1 \mathrm{f}$ & $27.7(7.2)$ & \\
\hline Olfactory Threshold & & & & & & \\
\hline Geddes et al. 1991 & 5 way forced choice & $?$ & 24 Schiz & $16 \mathrm{~m}, 8 \mathrm{f}$ & 38.5 [20-66] & 0.8126 \\
\hline & $\begin{array}{l}\text { ascending method of } \\
\text { limits (AML): }\end{array}$ & & 23 Control & $17 \mathrm{~m}, 6 \mathrm{f}$ & $37.1[21-62]$ & \\
\hline & Androstenone & & & & & \\
\hline Isseroff et al. 1987 & 3 way forced choice, & $4.4(1.58)$ & 42 Schiz & $22 \mathrm{~m}, 20 \mathrm{f}$ & $30.1(6.4)$ & 1.0791 \\
\hline & AML: Isoamyl Acetate & $6.5(2.19)$ & 40 Control & $20 \mathrm{~m}, 20 \mathrm{f}$ & $30(6.4)$ & \\
\hline Isseroff et al. 1987 & 3 way forced choice, & $?$ & 42 Schiz & $22 \mathrm{~m}, 20 \mathrm{f}$ & $30.1(6.4)$ & 0.3145 \\
\hline & AML: Androstenone & & 40 Control & $20 \mathrm{~m}, 20 \mathrm{f}$ & $30(6.4)$ & \\
\hline Serby et al. 1990 & 3 way forced choice, & $?$ & 14 Schiz & $14 \mathrm{~m}$ & matched, & 1.4433 \\
\hline & AML: Geraniol & & 14 Control & $?$ & {$[40-49]$} & \\
\hline Olfactory Discrimination & & & & & & \\
\hline Dunn and Weller 1989 & Match to sample, & $?$ & 15 Schiz & $13 \mathrm{~m}, 2 \mathrm{f}$ & $54.2[28-71]$ & 0.0177 \\
\hline & four odor sets & & 15 Control & $13 \mathrm{~m}, 2 \mathrm{f}$ & $52.9[25-65]$ & \\
\hline Sreenivasan et al. 1987 & Match to sample & $2.7(1.0)$ & 32 Schiz & $?$ & {$[15-45]$} & 0.8691 \\
\hline Olfactory Memory & & $3.5(0.8)$ & 30 Control & $?$ & {$[15-45]$} & \\
\hline Wu et al. 1993 & Match to sample, & $9.3(2.6)$ & 20 Schiz & $19 \mathrm{~m}, 1 \mathrm{f}$ & $32.1(9.3)$ & 1.248 \\
\hline & 15 odor sets & $12.0(1.63)$ & 24 Control & $23 \mathrm{~m}, 1 \mathrm{f}$ & $27.7(7.2)$ & \\
\hline
\end{tabular}

${ }^{a}$ Number listed is less than total reported due to exclusions by the authors.

${ }^{b}$ Reported as listed in article.

${ }^{c}$ Based on total sample.

? data not available. 
ability to differentiate between a set of odorants. The two studies included in the analysis used a match to sample task that required the subject to pick out the target odor from a series of odorants, all of which were identical except for one (i.e., "odd man out" type procedure). Accurate performance on discrimination tasks is thought to require intact acuity but not identification of the odorant (Martzke et al. 1997).

Only one of the two published studies examining olfactory recognition memory met criteria for inclusion in the meta-analysis. Inclusion in this domain required an assessment technique in which the subject is asked to distinguish, between a choice of odorants, the one that was presented to him or her before. These methods primarily were characterized by match-to-sample type tests.

\section{Statistical Analysis}

Analyses were conducted according to procedures suggested by Rosenthal (1986) and Hedges and Olkin (1985). The dependent measure was effect size for tests of olfactory: (i) identification; (ii) detection threshold; (iii) discrimination; and (iv) recognition memory expressed in Cohen's $d$ (Cohen 1977; Glass 1977). The $d$ score is the difference between patient and control group means, within each study or comparison, expressed in standard deviation units. Where the means and standard deviations were not reported, $t, F, r$, or $\chi^{2}$ statistics were converted to $d$ using formulas provided by Glass (1977). By expressing effect size in standard deviation units, we were able to make a direct comparison of outcomes across studies. Each analysis was conducted in several steps. First, Hedges $g$ was derived for each study by subtracting the mean control olfactory score $\left(m_{c}\right)$ from the mean patient olfactory score $\left(m_{p}\right)$ and dividing it by the pooled standard deviation $(s)$ using the formula (Hedges and Olkin 1985; Rosenthal 1994) [Equation (1)]:

$$
g=\frac{m_{p}-m_{c}}{s}
$$

the pooled standard deviation (s) was computed as follows [Equation (2)]:

$$
s=\left\{\left[\left(n_{p}-1\right)\left(s_{p}\right)^{2}+\left(n_{c}-1\right)\left(s_{c}\right)^{2}\right] /\left(n_{p}+n_{c}-2\right)\right\}
$$

where $n_{p}$ and $n_{c}$ are the number of observations in the patient and control groups, respectively, and $s_{p}$ and $s_{c}$ are the standard deviations for the patient and control groups, respectively.

Although Hedges $g$ is an estimate of effect size, the $g$-statistic is known to overestimate the population effect size when sample sizes are small (Rosenthal 1994). In order to correct for this bias, Hedges $g$ was subsequently transformed into an unbiased measure of effect size, Cohen's $d$ (Hedges 1981; Hedges and Olkin 1985).
Individual values of $d$ were hereafter combined across studies and weighted according to their variance $(v)$ using the formulas [Equation (3); Equation (4)]:

$$
v=\frac{n_{1}+n_{2}}{n_{1}+n_{2}}+\frac{d^{2}}{2\left(n_{1}+n_{2}\right)}
$$

and

$$
w_{i}=\frac{1}{v_{i}}
$$

where $w_{i}$ represents the individual weight for a given study (Hedges and Olkin 1985).

Potential differences in effect size between olfactory domains were analyzed using the method of Hedges and Olkin (1985). This procedure computes mean weighted effect sizes and 95\% confidence intervals (CI) for each variable subset and allows for the testing of the influence of each individual factor on the overall results.

For further discussion and details concerning metaanalytic techniques, the reader is referred to the works of Cooper and Hedges (1994), Hedges and Olkin (1985), Hunter et al. (1982), and Rosenthal (1986).

\section{Moderator Variables}

Gender, smoking history, and medication status have been cited as possible contributors or moderator variables in the expression of olfactory deficits in schizophrenia. To address these issues, effect sizes were calculated separately for gender when these data were reported. Medication status for subjects in each study was also coded as: $0=$ unmedicated, $1=$ mixed (some patients on medication, some off), and 2 = medicated. Smoking status was calculated as the percentage of the total sample of subjects who smoked.

\section{RESULTS}

Table 2 shows the mean weighted effect sizes $\left(d_{+}\right)$for schizophrenia patients on odor identification, odor de-

Table 2. Tests of Categorical Model for Type of Olfactory Domain

\begin{tabular}{lrccr}
\hline Class & k & $\boldsymbol{d}_{+}$ & $\mathbf{9 5 \%} \mathbf{C I}$ & \multicolumn{1}{c}{$\boldsymbol{Q}_{\mathbf{w}}$} \\
\hline Identification & 18 & 0.94 & $0.82<\delta<1.07$ & $56.2^{a}$ \\
Threshold & 4 & 0.78 & $0.52<\delta<1.04$ & 8.4 \\
Discrimination & 2 & 0.57 & $0.15<\delta<0.99$ & 3.5 \\
Memory & 1 & 1.24 & $0.59<\delta<1.89$ & -0.0 \\
\hline
\end{tabular}

$Q_{B}=4.73 ; p=0.19$.

${ }^{a} p<.001$.

Class, type of olfactory measure; $\mathrm{k}$, number of studies in analysis; $d_{+}$ mean weighted effect size; $95 \%$ CI, 95 percent confidence interval for $d_{+}$; $Q_{w}$, within-class effect; $Q_{B}$, between-class effect. 
tection threshold, odor discrimination, and odor memory measures. The composite effect sizes for tasks of odor identification and memory in patients would be considered "very large" in that they were above the criteria of a large effect $(\geqslant 80)$, as described by Cohen's (1977) metric. Deficit in odor detection threshold fell in the upper end of the moderate impairment while discrimination deficit fell in the moderate range.

Table 2 also presents the mean weighted effect sizes, confidence intervals, and homogeneity statistics for the four domains of olfactory function. Results indicated that across the four domains integrated, olfactory abilities in patients with schizophrenia were significantly impaired $\left(d_{+}=0.90,95 \% \mathrm{CI}=0.79<\delta<1.01\right)$, but that as expected this effect was inconsistent $(Q[24]=72.9$, $p<.001)$. Therefore, we attempted to account for this variability in the effect sizes by contrasting type of olfactory domain assessed. Categorical contrasts between the four different olfactory domains did not yield any significant differences $\left(Q_{B}[3]=4.73, p=.19\right)$, indicating similar levels of impairment across test types.

As can be seen in Table 2, the magnitude of impairment seen on tests of odor identification appear somewhat larger than that seen in threshold or discrimination tasks, and roughly comparable to that of memory. It should be noted, however, that only one study represented the domain of odor memory, strongly limiting the conclusions to be drawn from this portion of the analysis.

Within the domain of odor identification, analysis of effect size homogeneity revealed significant heterogeneity of effect sizes $(Q[17]=54.1, p<.001)$. Outlier analysis identified two significant outliers that contributed substantially to the observed heterogeneity. Stepwise exclusion of these two studies from the analysis resulted in a homogeneous grouping of effect sizes that could be expressed as a composite $(Q[15]=21.4, p=$ .12). Further investigation into these outliers revealed that both studies differed from the others in the analysis in that they studied elderly patients and controls (Kopala et al. 1995b; Moberg et al. 1997a). Even after excluding these two studies the composite effect size remained significant and robust $\left(d_{+}=0.84,95 \% \mathrm{CI}=0.71<\right.$ $\delta<0.98$ ).

Consistent with the analysis for odor identification tasks, significant heterogeneity was also observed among effect sizes for odor detection threshold measures $(Q[3]=$ $8.44, p=.037$ ). Removal of the one outlier (Isseroff et al. 1987) resulted in a homogeneous grouping of effect sizes $(Q[2]=1.57, p=.45)$. With the exception of using androstenone (a testosterone metabolite excreted in human sweat) as a stimulus, there were no other differentiating characteristics or moderator variables noted in this outlying study. Despite the exclusion of one study, the composite effect size remained significant $\left(d_{+}=1.04,95 \% \mathrm{CI}=0.72<\delta<1.37\right)$, indicating a significant deficit in odor detection thresholds relative to healthy controls.

Analysis of effect size homogeneity within the odor discrimination domain nearly reached significance $(Q[1]=3.55, p=.059)$ due to the range of effect sizes across the two obtained studies. While these studies used a similar methodology to assess odor discrimination, the types of odorants used in each study varied quite widely, perhaps explaining the discrepancy between the two effect sizes.

\section{Moderator Variable Analysis}

Gender. Examination of gender effects for tests of odor discrimination and memory was not possible due to the limited number of studies included within these domains. Analysis of studies assessing odor identification revealed homogenous effect sizes across gender $(Q[9]=$ 7.6, $p=.57)$ indicating no differential deficit in odor identification performance between male and female patients with schizophrenia. Indeed, the mean weighted effect sizes for odor identification performance for male $\left(d_{+}=0.80,95 \% \mathrm{CI}=0.53<\delta<1.06\right)$ and female $\left(d_{+}=\right.$ $0.81,95 \% \mathrm{CI}=0.50<\delta<1.12)$ patients were virtually identical $\left(\chi^{2}=0.007, p=.93\right)$. Similarly, mean weighted effect sizes for odor detection threshold tasks were also homogeneous $(Q[3]=5.6, p=.12)$, with effect sizes being nearly equivalent in both male $\left(d_{+}=0.63,95 \% \mathrm{CI}=\right.$ $0.19<\delta<1.08)$ and female $\left(d_{+}=0.69,95 \% \mathrm{CI}=0.24<\right.$ $\delta<1.15)$ patients $\left(\chi^{2}=0.03, p=.85\right)$.

Medication Status. In the domain of odor identification ( $\mathrm{N}=18$ studies), analysis of effect size by medication status did not reveal significant differences between medicated, unmedicated or mixed groups $\left(Q_{\mathrm{B}}[2]=4.62\right.$, $p=.09)$. The same result was obtained when detection thresholds $(\mathrm{N}=4$ studies $)$ were examined $\left(Q_{\mathrm{B}}[1]=\right.$ $0.58, p=.44)$ and when all four olfactory domains were considered together $(\mathrm{N}=24$ studies $)\left(Q_{\mathrm{B}}[2]=2.17, p=\right.$ $.33)$.

Smoking Status. Analysis of smoking effects in odor threshold, discrimination or memory tasks was not possible given the small number of studies in each of these domains that reported smoking data. However, evaluation of the relationship between the smoking status and effect size for odor identification tasks alone $(\mathrm{N}=11$ studies) was not significant ( $r=0.43, p=.18$ ). When effect sizes were collapsed across all four olfactory domains ( $\mathrm{N}=14$ studies), smoking had, at best, only a marginal association with effect size $(r=0.49, p=.11)$.

\section{DISCUSSION}

Psychophysical studies have provided the basis of most of our knowledge about olfactory abilities in patients 
with schizophrenia. Controversy about the relationship of olfactory variables to other cognitive tasks, clinical symptoms and structural brain measures, however, continues to exist. Specifically, questions about differential deficit among olfactory tasks, gender differences and the effect of smoking and medication status continue to be invoked by several investigators. Results of the current meta-analysis appear to provide some clarity to these issues.

Our quantitative analysis of 18 studies of olfactory identification, four studies of odor detection threshold, two studies of odor discrimination, and one study of recognition memory in patients with schizophrenia revealed very large effects across all domains. While meta-analytic procedures are generally considered to be superior to traditional narrative reviews in the ability to quantify effect sizes, assess heterogeneity, and identify moderator variables, they do have limitations. First, meta-analytic procedures are most powerful when the calculations are based on a large number of studies. While this review represented an exhaustive review of the English-language literature, the current analysis was based on only 23 publications ( 25 studies). The number of studies utilizing odor detection threshold, discrimination, and memory measures was extremely limited and indicates a need for inclusion of multiple olfactory measures in future studies to more directly address the issue of possible differential deficits. Second, a number of authors have argued that the results of meta-analytic procedures are questionable when dependent variables and measures are heterogeneous. While studies of olfactory identification have generally utilized the UPSIT, measures of threshold, discrimination, and memory have been more heterogeneous. Examination of detection thresholds with a common method (e.g., single staircase (SS) and use of multiple reversals) and odorant type (e.g., phenyl ethyl alcohol) may increase comparability of olfactory deficits in patients with schizophrenia. For example, in the SS procedure a trial consists of the presentation of two $100-\mathrm{ml}$ glass sniff bottles to the subject in rapid succession. One bottle contains $20 \mathrm{ml}$ of a given concentration of phenyl ethyl alcohol dissolved in USP-grade mineral oil, whereas the other bottle contains mineral oil alone. For each trial, the subject is asked to indicate which of the two bottles in a pair produced the strongest sensation. The staircase is begun at the $-6.50 \log$ concentration step of a half-log step (vol/vol) dilution series extending from $-10.00 \mathrm{log}$ concentration to $-2.00 \mathrm{log}$ concentration. Initially, it is moved upward in full-log steps until correct detection occurs on five sets of consecutive trials at a given concentration level. If during this initial phase, an incorrect response is given on any trial, the staircase is moved upward a full-log step. Once the criterion of five consecutive correct responses is made on five trials, the staircase is reversed and sub- sequently moved up or down in half-log decrements, depending upon the subjects' performance on two pairs of trials (i.e., each pair consisting of a choice between diluent and odorant) at each concentration step. The geometric mean of the last four staircase reversal points of a total of seven serves as the estimate of threshold sensitivity (Doty and Kobal 1995). In both the SS and ascending method of limits (AML) procedures the direction of the initial stimulus presentation is made from weak to strong in order to reduce adaptation effects of prior stimulation.

An effect size is considered large when the value is $\geqslant 0.80$ (Cohen 1977). This implies a severe level of generalized olfactory deficit in schizophrenia patients relative to controls. However, the magnitude of deficit in odor identification in schizophrenia (mean $d_{+}=0.94$ ) is less than half of the impairment seen in Alzheimer's disease (mean $d=3.26$ ) and Parkinson's disease (mean $d=3.42$ ) (Mesholam et al. 1998). Two notable outliers in the current meta analytic review are studies of olfactory identification in elderly patients with schizophrenia (Kopala et al. 1995b; Moberg et al. 1997a). We have recently noted that in young and elderly patients with schizophrenia duration of illness is inversely correlated with UPSIT performance $(r=-0.92, p<0.001)$ independent of normal aging and gender effects as well as generalized cognitive impairment (Moberg et al. 1997b), suggesting that there are duration-linked changes in olfactory function in this disorder. Given an apparent progressive decline of olfactory identification abilities over the course of illness in patients with schizophrenia, and the fact that the outlying studies were largely comprised of elderly patients, it seems that the magnitude of olfactory deficit (and thus effect size) across the lifespan is considerably greater than in studies comprised of younger patients.

The finding of impaired odor detection thresholds in patients with schizophrenia is somewhat incongruent with prior theorizing and the lack of pathological findings in the OE of schizophrenia patients (Smutzer et al. 1998). While the notion of intact "peripheral" odor detection thresholds in patients with schizophrenia makes intuitive sense, it is currently based on very small number of controlled studies. Indeed, calculation of effect sizes from the available studies $(\mathrm{N}=4)$ indicates that the magnitude of deficit is not significantly different from that seen on tests of odor identification, discrimination, and memory. As such, odor detection thresholds appear to reflect a moderate deficit in these patients. It is clear from this analysis that further studies of odor detection thresholds need to be conducted before a differential deficit (or intact abilities) in these functions can be confidently declared. Similarly, a selective deficit in odor memory has also been described (Wu et al. 1993); however, Strauss (1994) makes a compelling argument that these differences may simply re- 
flect psychometric or statistical artifact. Indeed, the effect size in the Wu et al. (1993) study $(d=1.24)$ appears largely consistent with the deficit observed in odor identification.

While the current meta-analytic review did not support a diagnosis-specific sex difference in psychophysical olfactory testing, there are important reasons to expect such differences in olfactory function in schizophrenia. For example, estrogen has been shown to stimulate a significant increase in the density of 5-hydroxytryptamine2A (5-HT2A) binding sites in anterior frontal, cingulate and primary olfactory cortex in the nucleus accumbens, areas of the brain associated with the regulation of mood, mental state, cognition, and emotions (Fink et al. 1996). Non-significant trends toward poorer performance in male patients with schizophrenia have been reported (Seidman et al. 1997) suggesting that a diagnosis-specific sex effect, if present, is not robust and perhaps interacts with other moderator variables such as negative symptomatology or duration of illness. In light of the gender differences observed in other aspects of schizophrenia (Castle and Murray 1991; Seeman 1986; Seeman and Lang 1990), further investigation into gender effects on olfactory function seems warranted. Special attention has to be given to closely detailing menstrual cycle status, clinical subtypes, and hormone levels, as well as the documentation of differential olfactory impairment between men and women using physiologic neuroimaging. Notably, future studies should directly address the question of a diagnosis-specific sex effect in olfactory function in large samples using matched groups within sex to avoid any potential sampling bias or artifacts.

We recently examined the effect of acute administration of haloperidol (a dopamine $\mathrm{D}_{2}$ antagonist) and methylphenidate (a dopamine $\mathrm{D}_{1}$ agonist) on olfactory identification in eight healthy young controls in a prepost medication design (Swanson et al. 1997). Each subject also underwent a pre- and post-medication resting SPECT scan. Despite medication-induced changes in blood flow in frontal regions bilaterally, the results did not reveal any effect of either haloperidol $(p>.05)$ or methylphenidate $(p>.05)$ on olfactory identification performance, suggesting that the acute systemic manipulation of CNS dopamine by methylphenidate and haloperidol has minimal effects on olfactory identification abilities. While the impact of longer term antipsychotic treatment is not well understood, there is no compelling evidence in the literature of an association between medication status and performance on psychophysical olfactory measures. In addition, less is known about the impact of other medications on olfactory abilities (e.g., anticholinergics, etc.). Preliminary data examining the effects of anticholinergic medications on olfactory function in patients with schizophrenia have been negative (Brewer et al. 1996), but additional study is needed.
Specifically, closer examination of medication type and possible interactions will likely provide important information about the impact of these variables on olfactory function. Physiological measures of olfactory function through the use of PET, fMRI, or OERPs are also needed to further explore possible medication induced olfactory processing changes.

There is some evidence to indicate that smoking results in reduced olfactory sensitivity (Ahlström et al. 1987; Berglund and Nordin 1992). Other investigations, however, have found no effect of smoking on olfactory function per se, but have documented a reduction in the perception of nasal pungency, mediated by the trigeminal system (Cometto-Muñiz and Cain 1982). More recent data have demonstrated a dose-related effect of smoking on olfactory function that is reversible upon cessation of smoking (Frye et al. 1990). It should be noted that the magnitude of the adverse effects of smoking on olfactory function in healthy people is not large compared with the effects of such variables as age and sex. Despite the small dose-related smoking effect seen in controls, no study of olfactory functioning in patients with schizophrenia has observed any effect of smoking. Consistent with this finding, only marginal relationships between smoking status and olfactory effect sizes were observed upon meta-analytic review. However, in light of the findings of dose related effects of smoking on olfactory function in controls, simply dividing groups into "smokers" and "nonsmokers" may minimize any potential smoking effect through the inclusion of past smokers into the nonsmoking category. Future studies may help clarify this relationship by calculating "pack-years" for current- and past-smokers. Pack-years, or cigarette dose, is calculated by multiplying the number of packs smoked per day by the number of years that smoking occurred (Frye et al. 1990). The use of such a metric may help better define the relationship of this variable to olfactory function in patients with schizophrenia, especially since patients have been noted to be heavy smokers (Dalack and Meador-Woodruff 1996).

In the course of describing and quantifying the impairment in olfactory abilities in patients with schizophrenia, researchers are inevitably faced with the generalized cognitive impairment seen in persons suffering from this illness and how it interacts with the variable of interest (in this case olfactory function). Establishment of a differential or selective deficit (Chapman and Chapman 1978) in olfactory function in patients with schizophrenia requires demonstration of a specific dysfunction against the expected background of global cognitive impairment. As noted earlier, close consideration of psychophysical test reliability and task difficulty is required to identify any "selective deficit" in olfactory abilities. A number of studies, however, have reported the presence of olfactory dysfunction in pa- 
tients with schizophrenia which appear to be relatively independent of the endemic cognitive deficits (Kopala et al. 1995c; Moberg et al. 1997a; Moberg et al. 1997b; Seidman et al. 1992; Seidman et al. 1995; Seidman et al. 1997). Chapman and Chapman (1989) have recommended the use of standardized residualized scores or titration of accuracy by manipulation of test conditions to match for task difficulty. With the exception of the Kopala et al. (1995c) study, however, no other study has attempted to examine the severity of olfactory deficit compared to analog tasks of comparable complexity or through the use of other statistical "controls". Despite this fact, there has not been strong evidence of significant correlation between tests of olfactory function and tests of general neuropsychological abilities (Martzke et al. 1997). In summary, these data appear to generally support an independent deficit in olfactory processing in patients with schizophrenia.

Lastly, there have been relatively few studies that have directly examined the specificity of the olfactory deficit seen in patients with schizophrenia. Studies of patients with bipolar disorder (Hurwitz et al. 1988), depression (Amsterdam et al. 1987; Isseroff et al. 1994; Kopala et al. 1994; Warner et al. 1990), panic disorder (Kopala and Good 1996), and anorexia nervosa (Fedoroff et al. 1995; Kopala et al. 1995a) have generally indicated intact olfactory abilities relative to healthy controls. Direct contrasts, however, of schizophrenia patients with other groups experiencing similar levels of psychotic symptomatology has not yet been performed. In patients with obsessive-compulsive disorder, odor detection threshold sensitivity appears intact (Isseroff et al. 1994) whereas a mild deficit has been reported in odor identification abilities (Goldberg et al. 1991). Future studies directly comparing olfactory abilities in other neuropsychiatric disorders that impact similar brain systems will help gauge the magnitude and specificity of this deficit in patients with schizophrenia.

The relevance of the neural substrate, anatomy, and neurochemical organization of the olfactory system suggests that psychophysical measures may be able to tap limbic olfactory areas in a way other types of cognitive or sensory tasks cannot. As such, these investigations provide impetus for the use of olfactory probes in various neuroimaging paradigms that would allow for a more detailed analysis of brain structures and processes involved in this dysfunction. For example, the majority of preliminary neuroimaging studies in patients with schizophrenia appear to support greater association of olfactory deficits with right hemisphere neurophysiologic abnormalities (Bertollo et al. 1996; Clark et al. 1991; Malaspina et al. 1996). Expansion of this methodology with an emphasis on the use of odor stimulation tasks will doubtless advance our understanding of the olfactory dysfunction seen in this patient group.

\section{ACKNOWLEDGMENTS}

This research was supported in part by the Mental Health Clinical Research Center (MHCRC) on Schizophrenia (NIMH 43880), and the Smell and Taste Center (NIDCD PO-00161) at the University of Pennsylvania School of Medicine.

\section{REFERENCES}

Adams R, Victor M (1985): Principles of Neurology. New York, McGraw Hill

Ahlström R, Berglund B, Berglund U, Engen T, Lindvall T (1987): A comparison of odor perception in smokers, nonsmokers, and passive smokers. Am J Otolaryngol 8:1-6

Amsterdam J, Settle G, Doty R, Ableman E, Winokur A (1987): Taste and smell perception in depression. Biol Psychiatry 22:1477-1481

Andreasen NC, Ehrhardt JC, Swayze V, Alliger RJ, Yuh WTC, Cohen G, Ziebell S (1990): Magnetic resonance imaging of the brain in schizophrenia: The pathophysiologic significance of structural abnormalities. Arch Gen Psychiatry 47:35-44

Arnold SE, Smutzer GS, Trojanowski JQ, Moberg PJ (1998): Cellular and molecular neuropathology of the olfactory epithelium and central olfactory pathways in Alzheimer's disease and schizophrenia. Ann NY Acad Sci 855:762-775

Arnold SE, Trojanowski JQ (1996): Recent advances in defining the neuropathology of schizophrenia. Acta Neuropathol (Berl) 92:217-231

Becker E, Hummel T, Piel E, Pauli E, Kobal G, Hautzinger M (1993): Olfactory event-related potentials in psychosisprone subjects. Int J Psychophys 15:51-58

Berglund B, Nordin S (1992): Detectability and perceived intensity for formaldehyde in smokers and non-smokers. Chem Senses 17:291-306

Bertollo DN, Cowen MA, Levy AV (1996): Hypometabolism in olfactory cortical projection areas of male patients with schizophrenia: An initial positron emission tomography study. Psychiatry Res 60:113-116

Bradley EA (1984): Olfactory acuity to a pheromonal substance and psychotic illness. Biol Psychiatry 19:899-905

Brewer WJ, Edwards J, Anderson V, Robinson T, Pantelis C (1996): Neuropsychological, olfactory, and hygiene deficits in men with negative symptom schizophrenia. Biol Psychiatry 40:1021-1031

Bylsma FW, Moberg PJ, Doty RL, Brandt J (1997): Odor identification in Huntington's disease patients and asymptomatic gene carriers. J Neuropsychiat Clin Neurosci 9:598-600

Calev A, Venables PH, Monk AF (1983): Evidence for distinct verbal memory pathologies in severely and mildly disturbed schizophrenics. Schizophr Bull 9:247-264

Campbell IM, Gregson RAM (1972): Olfactory short term memory in normal, schizophrenic and brain-damaged cases. Austral J Psychol 24:179-185

Castle DJ, Murray RM (1991): The neurodevelopmental 
basis of sex differences in schizophrenia. Psychol Med 21:565-575

Chapman LJ, Chapman JP (1978): The measurement of differential deficit. J Psychiatry Res 14:303-311

Chapman LJ, Chapman JP (1989): Strategies for resolving the heterogeneity of schizophrenics and their relatives using cognitive measures. J Abnormal Psychol 98:357366

Clark C, Kopala L, Hurwitz T, Li D (1991): Regional metabolism in microsmic patients with schizophrenia. Can J Psychiatry 36:645-650

Cohen J (1977): Statistical Power Analysis for the Behavioral Sciences. New York, Academic Press, pp 25-26

Cometto-Muñiz JE, Cain WS (1982): Perception of nasal pungency in smokers and nonsmokers. Physiol Behav 29:727-731

Cooper H, Hedges LV (1994): The Handbook of Research Synthesis. New York, Russell Sage Foundation

Cotman CW, Monaghan DT, Ottersen OP, Storm-Mathisen J (1987): Anatomical organization of excitatory amino acid receptors and their pathways. Trends Neurosci 10:273-279

Dalack GW, Meador-Woodruff JH (1996): Smoking, smoking withdrawal and schizophrenia: Case reports and a review of the literature. Schizophr Res 22:133-141

Doty RL (1989): Influence of age and age-related diseases on olfactory function. Ann NY Acad Sci 561:76-86

Doty RL (1991a): Olfactory dysfunction in neurodegenerative disorders. In Getchell TV, Doty RL, Bartoshuk LM, Snow JB (eds), Smell and Taste in Health and Disease. New York, Raven Press, pp 735-751

Doty RL (1991b): Olfactory system. In Getchell TV, Doty RL, Bartoshuk LM, Snow JB (eds), Smell and Taste in Health and Disease. New York, Raven Press, pp 175-203

Doty RL, Bromley SM, Moberg PJ, Hummel T (1997): Laterality in human chemoreception. In Christman S (ed), Cerebral Asymmetries in Sensory and Perceptual Processing. Amsterdam, North Holland Publishing Co, pp 497-542

Doty RL, Brugger WE, Jurs PC, Orndorff MA, Snyder PJ, Lowry LD (1978): Intranasal trigeminal stimulation from odorous volatiles: Psychometric responses from anosmic and normal humans. Physiol Behav 20:175-185

Doty RL, Kobal G (1995): Current trends in the measurement of olfactory function. In Doty RL (ed.), Handbook of Olfaction and Gustation. New York, Marcel Dekker, pp 191-225

Doty RL, McKeown DA, Lee WW, Shaman P (1995): A study of the test-retest reliability of ten olfactory tests. Chemical Senses 20:645-656

Doty RL, Shaman P, Dann M (1984): Development of the University of Pennsylvania Smell Identification Test: A standardized microencapsulated test of olfactory function. Physiolog Behav 32:489-502

Doty RL, Smith R, McKeown DA, Raj J (1994): Tests of human olfactory function: Principal components analysis suggests that most measure a common source of variance. Percept Psychophys 56:701-707

Dunn TP, Weller MPI (1989): Olfaction in schizophrenia. Percept Mot Skills 69:833-834
Eichenbaum H, Morton TH, Potter H, Corkin S (1983): Selective olfactory deficits in case H.M. Brain 106:459-472

Ellison G (1995): The N-methyl-D-aspartate antagonists phencyclidine, ketamine and dizocilpine as both behavioral and anatomical models of the dementias. Brain Res Rev 20:250-267

Eskenazi B, Cain WS, Novelly RA, Mattson R (1986): Odor perception in temporal lobe epilepsy patients with and without temporal lobectomy. Neuropsychologia 24:553-562

Eslinger PJ, Damasio AR, van Hoesen GM (1982): Olfactory dysfunction in man: Anatomical and behavioural aspects. Brain Cog 1:259-285

Fedoroff IC, Stoner SA, Anderson AE, Doty RL, Rolls BJ (1995): Olfactory dysfunction in anorexia and bulemia nervosa. Int J Eat Disord 18:71-77

Fink G, Sumner BE, Rosie R, Grace O, Quinn JP (1996): Estrogen control of central neurotransmission: Effect on mood, mental state, and memory. Cell Mol Microbiol 16:325-344

Frye RE, Schwartz BS, Doty RL (1990): Dose-related effects of cigarette smoking on olfactory function. JAMA 263: 1233-1236

Fuster JM (1989): The Prefrontal Cortex: Anatomy, Physiology, and Neuropsychology of the Frontal Lobe, 2nd ed. New York, Raven Press

Geddes J, Huws R, Pratt P (1991): Olfactory acuity in the positive and negative syndromes of schizophrenia. Biol Psychiatry 29:774-778

Glass GV (1977): Integrating findings: The meta-analysis of research. Rev Res Educ 5:351

Goldberg ED, Goldberg RJ, Vannoppen B (1991): Sense of smell and obsessional behaviour. Am J Psychiatry 148:1757

Greer CA (1991): Structural organization of the olfactory system. In Getchell TV, Doty RL, Bartoshuk LM, Snow JB (eds), Smell and Taste in Health and Disease. New York, Raven Press, pp 65-81

Gur RE, Gur RC, Skolnick BE, Caroff S, Obrist WD, Resnick S, Reivich M (1985): Brain function in psychiatric disorders: III. Regional cerebral blood flow in unmedicated schizophrenics. Arch Gen Psychiat 42:329-334

Gur RE, Mozley PD, Resnick S, Mozley LH, Shtasel DL, Gallacher F, Arnold SE, Karp JS, Alavi A, Reivich M, Gur RC (1995): Resting cerebral glucose metabolism and clinical features of schizophrenia. Arch Gen Psychiat 52:657-667

Halász N (1990): The Vertebrate Olfactory System. Chemical Neuroanatomy, Function and Development. Budapest, Akadémiai Kiadó

Harrison PJ, Pearson RC (1989): Olfaction and psychiatry. Br J Psychiatry 155:822-828

Hedges LV (1981): Distribution theory for Glass's estimator of effect size and related estimators. J Ed Stat 6:107-128

Hedges LV, Olkin I (1985): Statistical Methods for MetaAnalysis. New York, Academic Press

Houlihan DJ, Flaum M, Arnold SE, Keshavan M, Alliger R (1994): Further evidence for olfactory identification deficits in schizophrenia. Schizophr Res 12:179-182 
Hunter JE, Schmidt FL, Jackson GB (1982): Meta-Analysis: Cumulating Findings across Research. Beverly Hills, CA, Sage

Hurwitz T, Clark C (1990): Response (to Warner et al. 1990). Biol Psychiatry 23:448

Hurwitz T, Kopala L, Clark C, Jones B (1988): Olfactory deficits in schizophrenia. Biol Psychiatry 23:123-128

Isseroff RG, Luca-Haimovici K, Sasson Y, Kindler S, Kotler M, Zohar J (1994): Olfactory sensitivity in major depressive disorder and obsessive compulsive disorder. Biol Psychiatry 35:798-802

Isseroff RG, Stoler M, Ophir D, Lancet D, Sirota P (1987): Olfactory sensitivity to androstenone in schizophrenic patients. Biol Psychiatry 22:922-925

Jones-Gotman M, Zatorre RJ (1988): Olfactory identification deficits in patients with focal cerebral excision. Neuropsychologia 26:387-400

Kopala LC, Clark CC, Bassett A (1991): Olfactory deficits in schizophrenia and chromosome 5. Biol Psychiatry 29:730-734

Kopala L, Clark C, Hurwitz TA (1989): Sex differences in olfactory function in schizophrenia. Am J Psychiatry 146:1320-1322

Kopala LC, Clark C, Hurwitz T (1992): Olfactory deficits in neuroleptic naive patients with schizophrenia. Schizophr Res 8:245-250

Kopala LC, Good KP (1996): Olfactory identification ability in patients with panic disorder. J Psychiatry Neurosci 21(5):340-342

Kopala LC, Good K, Goldner EM, Birmingham CL (1995a): Olfactory identification ability in anorexia nervosa. J Psychiatry Neurosci 20:283-286

Kopala LC, Good KP, Honer WG (1994): Olfactory hallucinations and olfactory identification ability in patients with schizophrenia and other psychiatric disorders. Schizophr Res 12:205-211

Kopala LC, Good K, Honer WG (1995b): Olfactory identification ability in pre- and postmenopausal women with schizophrenia. Biol Psychiatry 38:57-63

Kopala L, Good K, Martzke J, Hurwitz T (1995c): Olfactory deficits in schizophrenia are not a function of task complexity. Schizophr Res 17:195-199

Kopala LC, Good KP, Torrey EF, Honer WG (1997a): Olfactory function in monozygotic twins discordant for schizophrenia. Am J Psychiatry 155:134-136

Kopala LC, Lewine R, Good KP, Fluker M, Martzke JS, Lapointe JS, Honer WG (1997b): Clinical features of schizophrenia in a woman with hyperandrogenism. J Psychiat Neurosci 22:56-60

Kratskin IL (1995): Functional anatomy, central connections, and neurochemistry of the mammalian olfactory bulb. In Doty RL (ed), Handbook of olfaction and gustation. New York, Marcel Dekker, pp 103-126

Kwapil TR, Chapman JP, Chapman LJ, Miller MB (1996): Deviant olfactory experiences as indicators of risk for psychosis. Schiz Bull 22:371-382

Lewis PR, Shute CCD (1967): The cholinergic limbic system: Projections to the hippocampal formation, medial cortex, nuclei of the ascending cholinergic reticular system, and the subfornical organ and supra-optic crest. Brain 90:521-539
Malaspina D, Lignelli A, Pererra G, Marshall R, Gorman J, van Heertum R (1996): SPECT brain activation by odor discrimination in schizophrenia and controls. Presented at the 35th Annual Meeting of the Academy of Neuropsychopharmacology, San Juan, Puerto Rico

Malaspina D, Wray AD, Friedman JH, Amador X, Yale S, Hasan A, Gorman JM, Kaufmann CA (1994): Odor discrimination deficits in schizophrenia: Association with eye movement dysfunction. J Neuropsychiat Clin Neurosci 6:273-278

Margolis FL, Getchell TV (1988): Molecular Neurobiology of the Olfactory System: Molecular, Membranous, and Cytological Studies. New York, Plenum Press

Martinez BA, Cain WS, de Wijk RA, Spencer DD, Novelly RA, Sass KJ (1993): Olfactory functioning before and after temporal lobe resection for intractable seizures. Neuropsychology 7:351-363

Martzke JS, Kopala LC, Good KP (1997): Olfactory dysfunction in neuropsychiatric disorders: Review and methodological considerations. Biol Psychiatry 42:721-732

McCarley RW, Faux SF, Shenton ME, Nestor PG, Adams J (1991): Event-related potentials in schizophrenia: Their biological and clinical correlates and a new model of schizophrenic pathophysiology. Schizophr Res 4:209231

Mesholam RI, Moberg PJ, Mahr RN, Doty RL (1998): Olfaction in neurodegenerative disease: A meta-analytic review of olfactory functioning in Alzheimer's and Parkinson's disease. Arch Neurol 55:84-90

Moberg PJ, Doty RL (1997): Olfactory function in Huntington's disease patients and at-risk offspring. Int J Neurosci 89:133-139

Moberg PJ, Doty RL, Mahr RN, Mesholam RI, Arnold SE, Turetsky BI, Gur RE (1997a): Olfactory identification in elderly schizophrenia and Alzheimer's disease. Neurobiol Aging 18:163-167

Moberg PJ, Doty RL, Turetsky BI, Arnold SE, Mahr RN, Gur RC, Bilker W, Gur RE (1997b): Olfactory identification deficits in schizophrenia: Correlation with duration of illness. Am J Psychiatry 154:1016-1018

Moran DT, Rowley JC, Jafek BW, Lovell MA (1982): The fine structure of the olfactory mucosa in man. J Neurocytol 11:721-746

Nordin S, Murphy C (1996): Impaired sensory and cognitive olfactory function in questionable Alzheimer's disease. Neuropsychology 10:113-119

Pantelis C, Brewer W (1995): Neuropsychological and olfactory dysfunction in schizophrenia: Relationship of frontal syndromes to syndromes of schizophrenia. Schizophr Res 17:35-45

Park S, Schoppe S (1997): Olfactory identification deficit in relation to schizotypy. Schizophr Res 26:191-197

Potter H, Butters N (1980): An assessment of olfactory deficits in patients with damage to prefrontal cortex. Neuropsychologia 18:621-628

Potter H, Nauta WJH (1979): A note on the problem of olfactory associations of the orbitofrontal cortex in the monkey. Neuroscience 4:361-367

Price JL (1987): The central olfactory and accessory olfactory systems. In Finger TE, Silver WL (eds). Neurobiology of Taste and Smell. New York, Wiley 
Price JL (1990): Olfactory system. In Paxinos G (ed), The Human Nervous System. San Diego, CA, Academic Press, pp 979-998

Rausch R, Serafetinides EA (1975): Specific alteration of olfactory function in humans with temporal lobe lesions. Nature 225:557-558

Rosenthal R (1986): Meta-Analytic Procedures for Social Research. London, Sage Publications

Rosenthal R (1994): Parametric measures of effect size. In Cooper H, Hedges LV (eds), The Handbook of Research Synthesis. New York, Russell Sage Foundation, pp 231244

Saykin AJ, Gur RC, Gur RE, Mozley D, Mozley LH, Resnick SM, Kester DB, Stafiniak P (1991): Neuropsychological function in schizophrenia: Selective impairment in memory and learning. Arch Gen Psychiat 48:618-624

Seeman MV (1986): Current outcome in schizophrenia: Women vs. men. Psychiat Scand 73:609-617

Seeman MV, Lang M (1990): The role of estrogens in schizophrenia gender differences. Schiz Bull 16:185-194

Seidman LJ, Goldstein JM, Goodman JM, Koren D, Turner WM, Faraone SV, Tsuang MT (1997): Sex differences in olfactory identification and Wisconsin Card Sorting performance: Relationship to attention and verbal ability. Biol Psychiatry 42:104-115

Seidman LJ, Oscar-Berman M, Kalinowski AG, Ajilore O, Kremen WS, Faraone SV, Tsuang MT (1995): Experimental and clinical neuropsychological measures of prefrontal dysfunction in schizophrenia. Neuropsychology 9:481-490

Seidman LJ, Talbot NL, Kalinowski AG, McCarley RW, Faraone, SV, Kremen WS, Pepple JR, Tsuang MT (1992): Neuropsychological probes of fronto-limbic dysfunction in schizophrenia: Olfactory identification and Wisconsin Card Sorting performance. Schizophr Res 6:55-65

Serby M, Larson P, Kalkstein D (1990): Olfactory sense in psychoses. Biol Psychiatry 28:829-830

Serby MJ, Larson PM, and Kalkstein D (1992): Olfaction and neuropsychiatry. In Serby MJ, Chobor KL (eds), Science of Olfaction. New York, Springer-Verlag, pp 559-581

Serby M, Mohan C, Aryan M, Williams L, Mohs RC, Davis KL (1996): Olfactory identification deficits in relatives of Alzheimer's disease patients. Biol Psychiatry 39:375-377

Shenton ME, Kikinis R, Jolesz FA, Pollak SD, LeMay M,
Wible CG, Hokama H, Martin J, Metcalf D, Coleman M, McCarley RW (1992): Abnormalities of the left temporal lobe and thought disorder in schizophrenia: A quantitative magnetic resonance imaging study. N Engl J Med 327:604-612

Shute CC, Lewis PR (1967): The ascending cholinergic reticular system: Neocortical, olfactory, and subcortical projections. Brain 90:497-520

Smutzer G, Trojanowski JQ, Lee VM-Y, Arnold SE (1998): Human olfactory mucosa in schizophrenia. Ann Otol Rhinol Laryngol 107:349-355

Sreenivasan KV, Abraham A, Verghese A (1987): Right temporal lobe functions in psychiatric disorders. Ind J Clin Psychol 14:40-42

Strauss ME (1994): Olfactory memory deficits in schizophrenia: Differential deficit or psychometric artifact. Schizophr Res 12:89-90

Swanson CL, Moberg PJ, Turetsky BI, Mozley D, Nienow TM, Doty RL, Gur RC, Gur RE (1997): Effects of Acute Administration of Haloperidol and Methylphenidate on Olfactory Performance. International Symposium on Olfaction and Taste XII and AChemS XIX. San Diego, CA, July 1997, pp 181

Tanabe T, Yarita H, Iino M, Ooshima Y, Takagi SF (1975): An olfactory projection area on orbitofrontal cortex of the monkey. J Neurophysiol 38:1269-1283

Turetsky BI, Cowell PE, Gur RC, Grossman RI, Shtasel DL, Gur RE (1995): Frontal and temporal lobe brain volumes in schizophrenia: Relationship to symptomatology and clinical subtype. Arch Gen Psychiat 52:1061-1070

Warner MD, Peabody CA, Csernansky JG (1990): Olfactory functioning in schizophrenia and depression. Biol Psychiatry 27:457-458

Weinberger DR, Berman KF, Suddath R, Torrey EF (1992): Evidence of dysfunction of a prefrontal-limbic network in schizophrenia: A magnetic resonance imaging and regional cerebral blood flow study of discordant monozygotic twins. Am J Psychiatry 149:890-897

West SE, Doty RL (1995): Influence of epilepsy and temporal lobe resection on olfactory function. Epilepsia 36:531-542

Wu J, Buchsbaum MS, Moy K, Denlea N, Kesslak P, Tseng H, Plosnaj D, Hetu M, Potkin S, Bracha S, Cotman C (1993): Olfactory memory in unmedicated schizophrenics. Schizophr Res 9:41-47 